\title{
Body art \\ Conceitos, práticas e uma visita de Gina Pane a Portugal
}

\section{Liliana Coutinho}
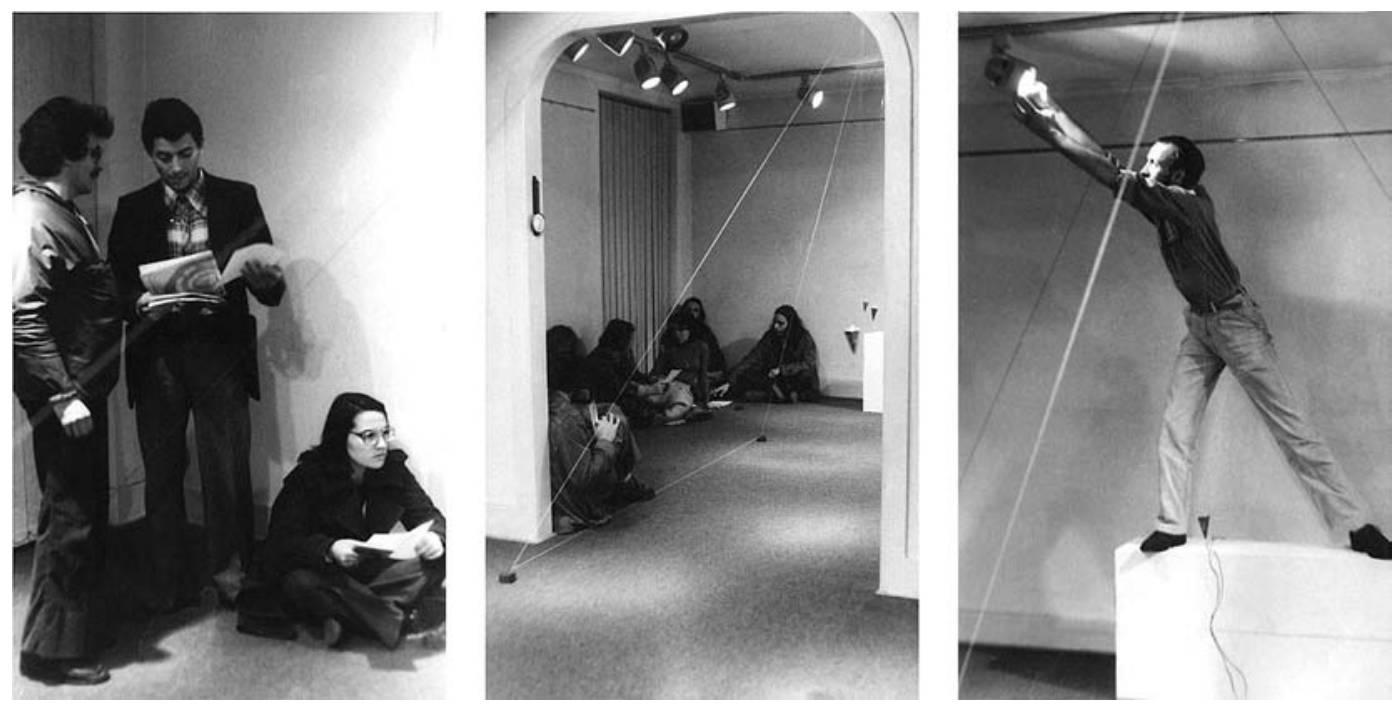

Três triângulos e som performance de José Conduto, Galeria Grafil, Lisboa, Março de 1978.

0 corpo é uma das âncoras a partir das quais é possivel pensar a experiência e a produção artística, nas suas diversas manifestações. Tal constitui mesmo um certo truismo, sobretudo após a emergência da performance art, processo iniciado entre nós a meio da década de sessenta, com um desenvolvimento mais intenso nas décadas de setenta e de oitenta', acompanhando transformações significativas, tanto nas artes plásticas como noutros territórios criativos, como foi o caso da poesia e da música experimentais.

Embora a performatividade seja um conceito operativo a partir do qual nos podemos relacionar com grande parte das manifestações artísticas contemporâneas, a presença do corpo surge como um requisito primário nas obras associadas à performance art. Num artigo publicado em 1981, no jornal nova-iorquino Village Voice, a crítica Sally Banes, acompanhando o movimento performativo novaiorquino, escrevia o seguinte:

Podemos definir a performance como um teatro total, desafiando categorizações, pois este inclui todas as artes; ou podemos defini-la como uma arte do tempo, viva, justamente o oposto da Gesamtkunstwerk; ou talvez possamos isolar apenas um aspecto singular da performance, tomando-a como uma acção social comum a inúmeras áreas artísticas: configuração estética da presença humana e um fazer público tornado arte. ${ }^{2}$
É neste contexto que surgem propostas radicais de um corpo presente, em acção, contribuindo para o aparecimento do conceito de body art. Em traços gerais, trata-se de uma prática que se inscreve literalmente nos limites do próprio corpo físico, tomando-o como objecto e não como imagem do sujeito que o transcende. Assim, situa-se também nos limites da formulação do sujeito enquanto corpo e enquanto individuo. Na body art, o corpo é reclamado como lugar de conhecimento e de produção de sentido.

Este texto não pretende abordar todas as práticas que possam ter contribuido para a existência, ou não, da body art em Portugal: seria necessário uma investigação mais demorada, na verdade ainda por fazer, que passasse pelas práticas performativas das décadas de sessenta a oitenta, e que tivesse mesmo em conta o modo como determinados artistas abordaram o corpo no âmbito de disciplinas mais convencionais. Pretendo apenas esboçar uma introdução às questões da body art, terminando com um episódio ilustrativo, ocorrido em finais da década de setenta. No entanto, para falar da body art em Portugal, justifica-se uma breve apresentação do contexto internacional, pois estamos perante a importação de um conceito, entre as muitas importações conceptuais feitas nessa época. Justifica-se ainda esta nota preliminar, porque estamos
'Para uma introdução cronológica às práticas performativas em Portugal, vale a pena consultar o catálogo do II Encontro Internacional de Performance, organizado por Fernando Aguiar, em 1988, na Amadora.

${ }^{2}$ Num artigo publicado no mesmo Village Voice, no dia 30 de Dezembro de 1981, Banes criticava também a ausência generalizada de recepção crítica de eventos no âmbito da Performance art. Sally Banes é historiadora da arte e o seu trabalho é um contributo muito importante para o conhecimento das artes performativas, tanto na área das artes plásticas, como na dança contemporânea. 
Três triangulos e som, performance de José Conduto, Galeria Grafil, Lisboa, Março de 1978

Detalhe da montagem fotográfica feita a partir da performance Três triangulos e som (José Conduto).

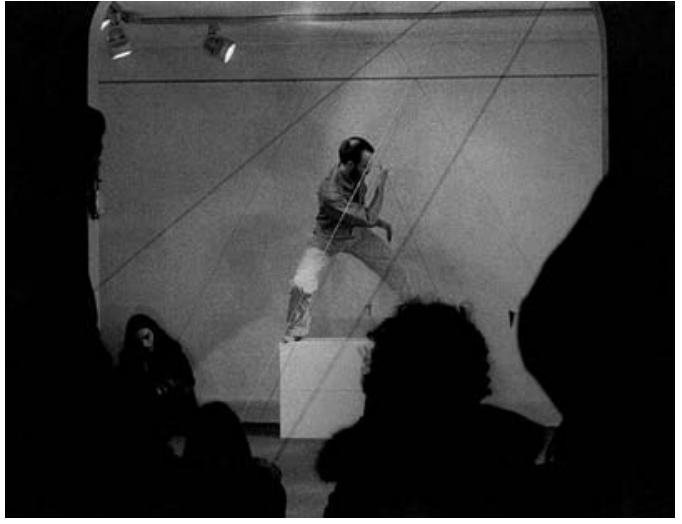

P REPA R I NG 1.3 .1978

\section{PERFORMING 15.3.1978}

perante práticas que se inscrevem num horizonte de recepção mais vasto do que o fornecido somente pelo contexto artístico português.

A body artsurge no contexto social e politico dos anos sessenta e setenta, numa atmosfera geral de experimentação. 0 território da estética aproximava-se então do território da vivência quotidiana e, também por esta via, da vivência concreta do corpo. Este surge como laboratório de experiências, com implicações na redefinição do próprio sujeito. Tais acções sobre o corpo vinham sublinhar a sua existência como objecto disponivel para usos, manipulações e inscrições, mas estas formas e intervenções sobre o corpo não deixam de ter consequências na mente que o habita, no intelecto que nele (e por ele) existe.

Ao explorar as relações de produção, estas novas práticas artísticas começam também por sair do quadro que tradicionalmente distinguia a arte do real concreto. Ao convocar os espectadores para discussões mais habituais em disciplinas relacionadas com as Ciências Sociais, a Psicologia ou a Filosofia, estas experiências abrem-se ao espaço público, anteriormente confinadas a domínios mais ou menos reservados e de circulação mais restrita, como o atelier do artista. 0 espaço público já não surge somente como lugar de exibição, mas também como espaço de produção; aspecto importante, pois o corpo em evidência na body art tende a ser um corpo público (e politicamente publicitado), também no sentido em que participa nas transformações acima mencionadas. Podemos assim compreender a body art em dois contextos complementares. Em primeiro lugar, como produto de uma determinada ascendência histórica, oscilando esta entre o expressionismo alemão, os eventos dadaistas e surrealistas, o teatro da crueldade de Artaud, as fotografias desfiguradas de Egon Schiele e as assinaturas de Piero
Manzoni sobre o corpo do modelo nu, prontamente usadas por Yves Klein. Em segundo lugar, a dramatização histórica da body art só pode ser cabalmente avaliada se tivermos em consideração a agenda política e libertária da década de sessenta, na qual esta começa a emergir com a especificidade que hoje the reconhecemos.

Nos Estados Unidos, entre os precursores da body art, merecem uma referência especial autores como Vito Acconci, o qual explorou de forma insistente as relações entre o corpo, o espaço (da galeria, da casa, do museu ou da rua) e as tensões assim criadas junto do público receptor. A sua presença em pequenas acções aproximam espectador, seja pela exposição dos seus gestos mais íntimos, seja através da exibição de uma hostilidade aparente. Acconci demonstrava assim a importância do campo de forças, físico e psíquico, que configura a relação entre o corpo do espectador e o corpo do artista. Por outro lado, numa das performances mais conhecidas de Chris Burden (Shoot, 1971), o criador chegou mesmo a atentar contra o próprio corpo, fazendo disparar um tiro sobre si mesmo. A cena de Shoot evidencia um corpo que resiste à dor e que apura os niveis de concentração, transcendendo a sua realidade fisica, mas submetendo-se simultaneamente à contingência bruta do real.

A body art resiste à sublimação do processo criativo mediante uma qualquer objectificação estética: este processo não seria indispensável para a existência da arte. Questionado sobre a razão da arte e sobre o fundamento da autonomia do fazer artístico, Dennis Oppenheim deslocava sugestivamente a questão do objecto para o "fazedor". A arte opõe-se assim à figuração kantiana de um fazer desinteressado. Consequentemente, interessase pelas demais experiências artísticas e, de um modo particular, pela body art. Como recordava Amelia Jones, tal sucede justamente após a "abertura dos circuitos do 


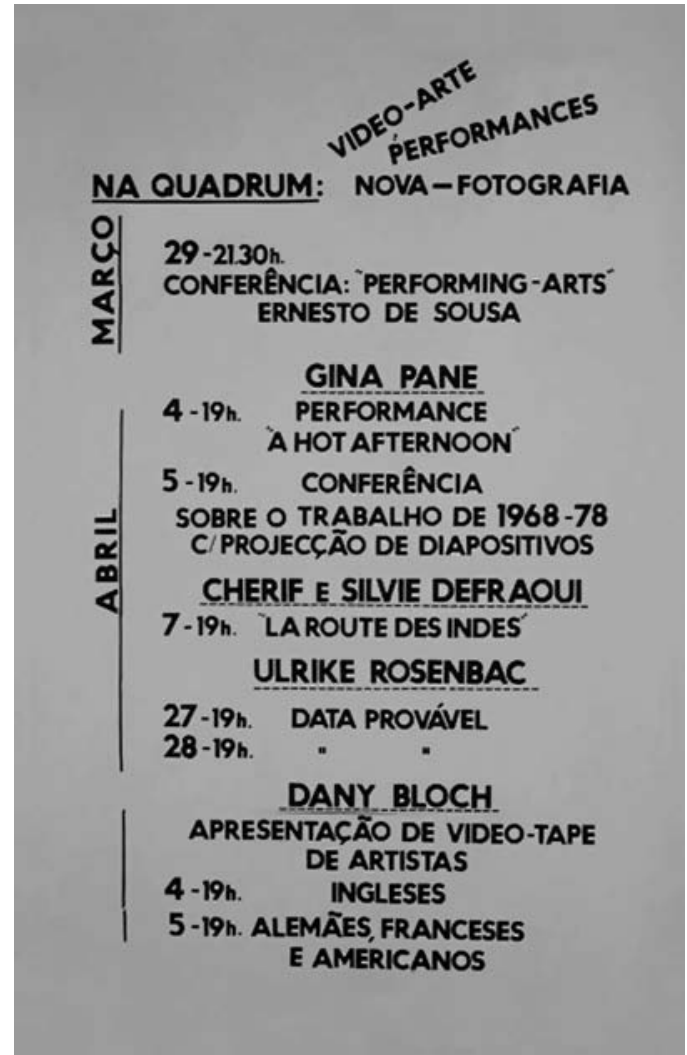

desejo que informam a produção e a recepção artísticas" (Jones 1998:5).

Estas tendências agudizam a consciência dos significados e dos valores culturais presentes na experiência artística. É certo que a crítica feminista estava então mais interessada nas políticas da representação, manifestando algumas reservas quanto à estetização do corpo. A representação de um corpo feminino dificilmente escapava aos mecanismos das suas representações convencionais, precisamente aqueles que deveriam ser desmontados. Daí a resistência da crítica às performances de Carolee Schnemann, nos anos sessenta. Mas esta apresentava-nos já um corpo-objecto, disponivel para uso e consciente das projecções e das representações a que um olhar exterior o poderia sujeitar. Deste modo, Schnemann marca uma diferença política clara, além de restringir o formalismo que na altura caracterizava algumas das experiências com o corpo.

Na Europa, a body art explorou sobretudo processos emotivos e expressivos, fazendo uso de um gestus com intuitos terapêuticos. Artistas como Otto Muhl, Gunter Brus, Arnulf Rainer e Valie Export interessam-se pelos processos psicológicos e psicanalíticos relacionados com o corpo. A imagem do indivíduo é destrinçada, exploramse as patologias do medo e do terror, procuram-se formas de libertar a energia reprimida, em busca de uma redenção pelo sofrimento. Dos seus trabalhos brotam gestos e sintomas que atestam o poder repressivo da máquina social. Importaria saber se este mergulho demasiado intenso num corpo somatizado não arrisca perder o distanciamento necessário à crítica. Como prevenir que a expressão da emoção se converta num fim em si mesmo, até à exaustão dos corpos? Na verdade, a participação física do público, frequentemente solicitada pela body art, pressupõe uma identificação que pode redundar em pura submissão.

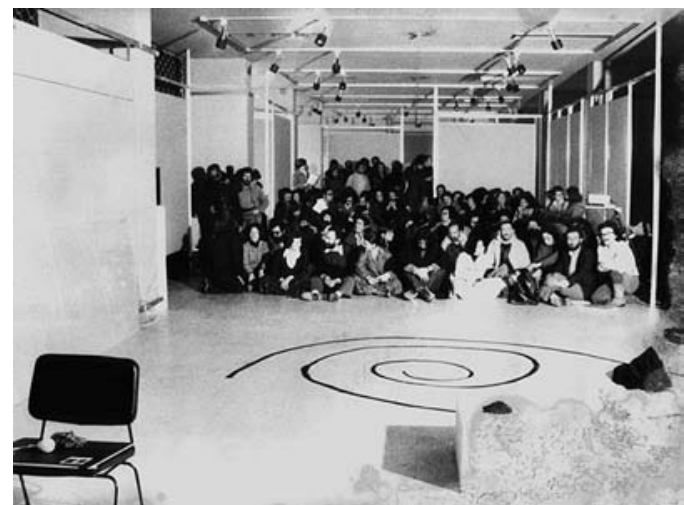

Cartaz com as actividades da Galeria Quadrum para os meses de Março e Abri de 1978.

Espectadores na Galeria Quadrum aguardam A Hot Afternoon, de Gina Pane, Lisboa (1978).
Mas o corpo deste espectador pode ser convocado de inúmeras formas. Em trabalhos como Meat Joy e mesmo no filme Fuses, Carolee Schnemann propõe-se abrir o olhar e explorar o seu lado "háptico" (táctil). Numa das pinturas-performances de Schneemann, a autora utiliza o seu corpo numa encenação de tintas, planos e colagens: Eye Body dá precisamente conta de um contacto pelo olhar e experimenta a recepção integral, envolvendo todo o corpo. Com a experiência "háptica" do olhar, o movimento de aproximação deixaria de se fazer estritamente no espaço. Se um certo olhar moderno cria uma distância entre os corpos e dessa mesma distância faz surgir a imagem, o olhar "háptico" percorreria todo esse espaço, ensaiando a própria destruição da ontologia mediadora das imagens. Mas este olhar "háptico" poderia ainda desdobrar-se e experimentar formas que transgridem a experiência quotidiana do olhar.

As intervenções da body art não são feitas somente no corpo do artista, elas projectam-se também no corpo dos espectadores. Vejamos este processo de aproximação ao corpo centrando a atenção no trabalho de Gina Pane, uma criadora europeia, cujas práticas contribuíram especialmente para a introdução da body art em Portugal. 0 balanço da vinda a Portugal de outros artistas oriundos do campo das artes performativas, está ainda por fazer, mas o seu contributo para divulgação da body art entre nós é inegável. Abordarei de seguida sobretudo o caso de Gina Pane, nome desde muito cedo associado à body art e um nome importante pela colaboração que veio a manter com o artista português José Conduto. A opção justificase também pela referência explícita à body art aquando da apresentação nacional desta artista, referência que se manteria no debate posterior à sua vinda a Lisboa. 0 próprio trabalho de José Conduto (1951-1980) testemunha esta realidade. Conduto desenvolveu durante a década de 
setenta um trabalho onde explorou o desenho, a instalação, o vídeo, o som e a performance, aparecendo em alguns contextos de recepção como trabalhando no campo da body art.

Em 1978, a galeria Quadrum recebeu durante os meses de Abril e de Maio uma série de eventos organizados por Ernesto de Sousa. Os eventos em causa foram sucessivamente apresentados como "arte-processo", "performances", "happenings", "novos meios (vídeo-arte, nova fotografia)", numa iniciativa que assim manifestava um notável propósito pedagógico, dirigido tanto ao público como aos artistas. 0 próprio organizador afirmaria explicitamente que a "única atitude ou função didáctica válida no nosso tempo é de natureza estética" (Sousa 1977: 51). Gina Pane apresentou a performance A Hot Afternoon 3 e logo de seguida orientou uma conferência que incluía uma mostra de diapositivos com o seu trabalho da década de 1968 a 1978, período durante o qual realizou os seus trabalhos mais próximos da body art. 0 corpo surge na sua obra numa proclamada revolta contra os sistemas estabelecidos, e a dor, conscientemente explorada, aparece como abertura à sensibilidade, no reverso de uma sociedade anestesiada - an-aesthesis -, sem sentido e sem sentimento. De novo, é através do corpo que se procura conhecer o sentido inscrito no corpo físico, esforço visivel quando Gina Pane crava espinhos nos braços, quando passa uma lâmina por cima das pálpebras ou quando se golpeia em forma de cruz, junto ao umbigo. Nestes gestos, a dor inscreve-se também num corpo psíquico, juntando-Ihe a memória dos símbolos evocados. Esta a razão para o seu uso insistente dos verbos "imprimir" e "fixar". Marcar é criar uma topologia de configurações mentais no corpo; e os nomes das suas performances referem-se também a essa relação: Psyché, Transfert, Escalade sanglant, Azionne sentimentale e Je.

O corpo objecto mostra-se na sua natureza dolorosa e precária. Também aqui são praticados actos de automutilação, cortes feitos na pele, apelando à consciência da dor e da morte. Serão estas performances versões actuais dos Memento mori medievais? É uma possibilidade: "A capacidade de fazer face conscientemente à dor e à morte faz parte da saúde do homem" (Tourraine 1991:55, tradução minha). Mais do que o sacrifício, importa notar que a alusão à dor e a sua expressão não ocorre como sintoma e representação de algo precedente, mas como algo que existe por direito próprio. Para além da experiência com o próprio corpo, são importantes as imagens psíquicas concebidas nas aç̧ões e nas diversas utilizações de técnicas fotográficas. A body art desafia assim o seu carácter transitório, seja pela inscrição de traços no corpo, evocando símbolos e referências culturais - de certo modo já culturalmente inscritas na nossa percepção -, seja pela utilização consciente da fotografia, como técnica que, na ausência da performer, perpetua a intencionalidade da performance original.

Se a arte conceptual se pretendeu livrar do peso institucional da arte, este lastro regressa frequentemente sob a forma documental. É através do documento que hoje temos acesso a uma série de obras efémeras realizadas nessas décadas. Pane lidava com esta situação logo desde a concepção das suas performances, as quais nunca foram pensadas como algo de puramente efémero, mas como parte de um processo, onde cabiam desenhos, fotografias e textos (preparatórios ou escritos mais tarde em montagens fotográficas). E é por este meio que a body art se projecta no corpo do espectador. Cada fotografia é feita num momento preciso da performance, para que a sua experiência seja acompanhada por uma "activação" na audiência. Como estímulo psicológico, a fotografia promove a performatividade do sujeito-espectador e provoca, mesmo que em diferido, a sua participação no ritual. Através da experiência estética há um sentido que se pretende criar e produzir, justamente no momento em que esta ocorre. Se os corpos da body artsão expressivos, no sentido em que se abrem como formas expressivas, as fotografias de Pane são tratadas do mesmo modo. Os diapositivos que Gina Pane mostrou na sessão da Galeria Quadrum, em 1978, não terão sido, portanto, simples documentação.

José Conduto terá assistido a estas apresentações, como atestam algumas anotações encontradas no seu espólio. Este artista, com uma vida (demasiado) breve, desenvolveu trabalhos no âmbito da instalação e da performance, insuficientemente conhecidos entre nós. Entre as anotações encontradas no seu espólio, contamse referências à body art e à experiência do corpo em geral. Este interesse de Conduto é confirmado pela experimentação extrema a que sujeitou o seu próprio 
corpo, mesmo fora de iniciativas artisticas. Estas experiências intensas com corpo, expostas após uma breve escavação biográfica, passaram de um modo muito depurado para as suas intervenções artísticas. A violência da sua intervenção sobre o corpo não é seguramente tão forte como a que na década seguinte se foi generalizando, mas uma década antes. Conduto já expusera a materialidade corporal de uma forma inédita entre nós, em performances que propunham um envolvimento físico e psíquico com o público implicando a utilização de uma série de materiais e de som.

Um pouco antes das apresentações de Gina Pane, no dia 10 Março de 1978, pelas 22 horas, o próprio Conduto apresentava Três triângulos e som, uma performance e uma instalação na Galeria Grafil. Sobre esta iniciativa, Conduto disse ter-se tratado de uma performance de natureza interrogativa, questionada pelo silêncio. Num texto apresentado no folheto de divulgação do evento, afirma o seguinte: "Todos nós, trabalhadores da dúvida, somos autores deste momento que a palavra não diz". Para além do dispositivo criado e do envolvimento dos espectadores - algo que pode ser verificado nas fotografias que hoje documentam a performance -, há todo um sentido que se busca através de meios que ultrapassam a linguagem, entrando no território da experiência e da presença dos corpos. Neste âmbito, o trabalho de Conduto interessa-se pela exploração da noção de espaço e de energia, apropriando-se intuitivamente de questões relacionadas com a física e com a metafísica de um corpo disperso, impropriamente desenhado. É neste contexto que surgem as suas experiências com o som. Em Via: Nota de comunicação, uma performance realizada em 1979, ainda na Galeria Quadrum, o som surge minimal, material, abrangendo um espectro que ultrapassa as nossas capacidades auditivas, para se inscrever na matéria vibrátil do nosso corpo, nos limites da percepção.

Tal como em Gina Pane, a fotografia surge também na obra de Conduto como um modo de perpetuar a experiência performativa: "Por exemplo: se eu era o médium numa acção, a fotografia era o médium numa instalação" ${ }^{\prime 3}$. De um modo aparentemente paradoxal, através da fixação do momento, Conduto pretendia demonstrar a existência do efémero, pois a "fixação da obra" era para si "outro nome do efémero". Simultaneamente, introduzia uma dimensão temporal na experiência com as suas montagens fotográficas. Também aqui o trabalho performativo recorre a outros meios, para além da fotografia, como desenhos, pinturas, serigrafias, e um inédito triângulo, figura geométrica, psíquica, amplamente explorada.

Ao que sabemos, são escassos os trabalhos radicais sobre o corpo desenvolvidos em território português durante a década de setenta. Não é de somenos o lugar histórico emoldurado pelo Estado Novo, muito reactivo às experiências com o corpo. A este propósito, recordo uma performance de João Vieira, no início da década de 70, seguramente uma das primeiras incursões nacionais no campo da body art. Intitulada Incorpório, a obra apresentava-se como uma espécie de ritual: uma mulher aparecia perante o público e, uma vez despida, deitavase dentro de um sarcófago com a forma do corpo escavada, sendo depois o conjunto lançado ao rio. 0 sarcófago conserva-se hoje no museu Vostell, de Malpartida, em Espanha. Mais do que a imagem do corpo feminino, João Vieira encena a sua incorporação no objecto artístico, contornando a materialidade ou evitando-a, fazendo do corpo imagem "incorpória", como sugerido no título, nos arredores da iconologia religiosa.

Incorpório lembra-nos a necessidade de pensar a experiência artística portuguesa a partir do modo como o corpo/sujeito se articulou com o político. Pensando na década de setenta, caberia perguntar, por exemplo, se a reconfiguração do corpo obedeceu entre nós a uma revolução tão suave como foi a de Abril. E importaria também questionar o modelo da visualidade e da participação do corpo no próprio processo da cognição, aspecto que tem no conhecimento das práticas artísticas um território central.

\section{Referências bibliográficas}

JONES, Amelia (1998), Body Art: Performing the Subject, Minneapolis, University of Minnesota Press.

SOUSA, Ernesto de (1977), "Uma criação consciente de situações" Colóquio Artes, n. ${ }^{34}$, Lisboa, F. C. G., pp. 45-53.

TOURRAINE, Liliane (1991), "Gina Pane: De la communication à la communion, une esthétique du partage", Colóquio Artes, n. 90, Lisboa, F. C. G., pp. 49-57.

\footnotetext{
${ }^{3}$ Todas as citações referentes a José Conduto são retiradas dos cadernos e folhas de esboços encontrados no espólio do artista. Naturalmente, o artista usa aqui o termo "médium" para se referir a meio de expressão.
} 